\title{
Key Factors Affecting a Technology Entrepreneur's Choice of Incubator or Accelerator
}

\author{
Diane A. Isabelle \\ "Ideas are like frog eggs: you've got to lay a thousand")
to hatch one. \\ Peter Drucker \\ Professor and management consultant
}

\begin{abstract}
Technology entrepreneurship rarely succeeds in isolation; increasingly, it occurs in interconnected networks of business partners and other organizations. For entrepreneurs lacking access to an established business ecosystem, incubators and accelerators provide a possible support mechanism for access to partners and resources. Yet, these relatively recent approaches to supporting entrepreneurship are still evolving. Therefore, it can be challenging for entrepreneurs to assess these mechanisms and to make insightful decisions on whether or not to join an incubator or accelerator, and which incubator or accelerator best meets their needs.

In this article, five key factors that entrepreneurs should take into consideration about incubators and accelerators are offered. Insights are drawn from two surveys of managers and users of incubators and accelerators. An understanding of these five key success factors (stage of venture, fit with incubator's mission, selection and graduation policies, services provided, and network of partners) and potential pitfalls will help entrepreneurs confidently enter into a relationship with an incubator or accelerator.
\end{abstract}

\section{Introduction}

What factors should technology entrepreneurs take into consideration when selecting a potential organization to support their development? What is the current landscape of incubators and accelerators in North America? In this article, insights on technology incubators and accelerators from an academic perspective, as well as a practitioner's perspective, are examined. Specifically, findings are presented from a recent survey of Canadian managers of incubators and accelerators and their client firms, conducted by the author, and from a recent survey of the North American business incubation industry (Knopp, 2012; tinyurl.com/buld3wd).

New technology ventures have to overcome several challenges to successfully commercialize their new ideas. Communities around the world have been look- ing for ways to encourage and support new-business development, in order to enhance economic development and create jobs. One such mechanism is business incubation and acceleration. Technology incubation, a variant of more traditional business incubation schemes, assists technology-oriented entrepreneurs in the start-up and early-development stage of their firms by providing workspace, shared facilities, and a range of business support services (OECD, 2010; tinyurl.com/ cb89gw3).

There is evidence that ventures associated with business incubators succeed at a greater rate than non-incubated ventures, however there is also evidence to the contrary (Scillitoe and Chakrabarti, 2010: tinyurl.com/c9o3lz4). Current gaps in the literature include: the lack of understanding of the different incubation models (Grimaldi and Grandi, 2005; tinyurl.com/cq3mf49), 


\section{Factors Affecting a Technology Entrepreneur's Choice of Incubator or Accelerator}

\section{Diane A. Isabelle}

the lack of attention focused on the incubatees and the incubation process, and the lack of peer-reviewed incubator-incubation impact studies or evaluation studies (Hackett and Dilts, 2004; tinyurl.com/blz8vgz; Hackett and Dilts, 2008; tinyurl.com/cuvvx2h).

The purpose of this article is to highlight five key areas of consideration to entrepreneurs who wish to use incubation or acceleration as a mechanism to accelerate the development and success of their new technologybased firm. The article is structured as follows. First, the concepts of incubators and accelerators are introduced. Second, insights from two recent surveys on incubators and accelerators are presented. Finally, conclusions and suggestions for future research are offered.

\section{Incubators}

The National Business Incubation Association (NBIA; nbia.org) defines a business incubator as "a business support process that accelerates the successful development of start-up and fledgling companies by providing entrepreneurs with an array of targeted resources and services." The OECD (2010; tinyurl.com/cb89gw3) defines technology business incubators, the focus of this article, as variants of more traditional business incubation schemes that assist technology-oriented entrepreneurs in the start-up and early development stages of their firms by providing workspace, shared facilities, and a range of business support services.

According to the NBIA (2009; tinyurl.com/3189xgy), the first business incubator in the United States opened in Batavia, New York in 1959, but the concept did not become popular with other communities until the late 1970s. Incubators also date back from the 1970s in the United Kingdom. Today, it is estimated that there are 1,400 business incubators in North America, about 200 in Mexico, 120 in Canada, and over 3,500 worldwide (Knopp, 2012; tinyurl.com/buld3wd). See Box 1 for examples of business incubators in North America.

Incubators have a long history as economic development tools. Throughout the world, universities, governments, and corporations are using incubators to accomplish a range of wealth-creation and social goals. In China, the former East Germany, and Ukraine, for example, incubators have been used to facilitate the transition to a market economy. In Israel, incubators have played a key role in helping to integrate immigrants from Russia and the former Soviet Bloc into the mainstream economy (NBIA, 2009; tinyurl.com/3l89xgy). Asia is a diverse region that has over 2,000 business incubat-
Box 1. Examples of incubators in North America

\section{United States}

- Cambridge Innovation Center (cic.us)

- TechColumbus (techcolumbus.org/incubator)

\section{Canada}

- MaRS Discovery District (marsdd.com)

-WaveFront (wavefrontac.com)

- Innovate Calgary (innovatecalgary.com)

\section{Ottawa region}

- Invest Ottawa (investottawa.ca)

- The Code Factory (thecodefactory.ca)

- Exploriem (exploriem.org)

- Incubators attached to federal government laboratories, such as the Communication Research Centre (crc.gc.ca) and the National Research Council (nrc-cnrc.gc.ca)

ors, mostly located in India, China, and East Asia. These incubators tend to be larger than those in the United States and the European Union, and are linked to universities and technology parks. They are grouped under the Asian Association of Business Incubators (AABI; aabi.info/about.asp).

Several regions of the world have been trying to replicate the success of Silicon Valley as an incubator of startups, mostly without much success of their own (Aaboen, 2009; tinyurl.com/c5gvvsw). However, in spite of the relatively long history of incubation, there is conflicting evidence as to whether or not incubation works. On the one hand, there is evidence that new firms associated with incubators have a higher survival rate and achieve a greater rate of growth, generally expressed in terms of sales and job creation, than non-incubated firms (Hackett and Dilts, 2004; tinyurl.com/blz8vgz). On the other hand, there is contradictory evidence that suggests little or no effect of incubation on the success of firms (Scillitoe and Chakrabarti, 2010; tinyurl.com/ c9o3lz4). However, measuring incubation success is difficult due to different selection criteria, lack of data, lack of access to data, local political influence, and the diversity of incubators. In its recent survey, NBIA notes that one-third of the respondents reported not collecting outcome data from graduates of their programs (Knopp, 2012; tinyurl.com/buld3wd). The lack of comparison with a control-group of non-incubated firms and the fact that selection criteria for incubatees might result in a selection bias constitute important challenges in the 


\title{
Factors Affecting a Technology Entrepreneur's Choice of Incubator or Accelerator
}

\author{
Diane A. Isabelle
}

measurement of impacts (Hackett and Dilts, 2004; tinyurl.com/blz8vgz). Further, most research has been descriptive, targeting a practitioner audience and focusing on incubators and their configuration (Hackett and Dilts, 2008; tinyurl.com/cuvvx2h). Given this, how should entrepreneurs discern important factors to take into consideration when deciding on an incubation process?

\section{Accelerators}

Over the last few years, a new model of providing assistance to new technology entrepreneurs has emerged, and it is generally referred to as a seed or venture accelerator (see examples in Box 2). Although there is no clear consensus on a definition of accelerators, this incubation model has a more explicit focus on accelerating the growth of firms than an incubator (Bosma and Stam, 2012; tinyurl.com/d7z3nah). An important distinction between incubators and accelerators appears to be their legal status. Incubators are typically not-for-profit organizations, whereas most accelerators are for-profit organizations designed to bring a return on investment to their sponsors by providing fast-test validation of business ideas, typically in fields such as mobile applications and related areas (Knopp, 2012; tinyurl.com/ buld3wd). The author's survey included eight Canadian not-for-profit organizations and two for-profit organizations. The NBIA survey reported that $93 \%$ of the respondents' accelerators were not-for-profit and $7 \%$ were for-profit. This distinction may affect a technology entrepreneurs' choice of assistance, because for-profit organizations are more likely to take equity in client firms. However, in practice, the terms incubator and accelerator are often used interchangeably. Furthermore, these two models have some similarities and operate in overlapping spaces with technology entrepreneurs.

\section{Insights for Entrepreneurs}

This section identifies five factors that technology entrepreneurs should take into consideration when evaluating business incubators and accelerators. These insights are drawn from three sources: two new research studies and the prior academic literature on incubators and accelerators. The first research study is the author's survey of ten managers of Canadian technology incubators and accelerators and six of their client firms, conducted in September 2012 via in-depth phone interviews. The second research study is an NBIA survey of 235 respondents to evaluate the state of the business incubation industry in North America (Knopp, 2012; tinyurl.com/buld3wd).
Box 2. Examples of accelerators in North America

United States

- Y Combinator (ycombinator.com)

- TechStars (techstars.com)

- DreamItVentures (dreamitventures.com)

- AngelPad (angelpad.org)

- Launchpad LA (launchpad.la)

\section{Canada}

- WaveFront (wavefrontac.com)

- Communitech (communitech.ca)

- InCubes (incubes.ca)

- GrowLab (growlab.ca)

- VentureLab (venturelab.ca)

The five key factors that entrepreneurs should consider when selecting a business incubator or accelerator are as follows:

\section{Stage of the new venture}

A very-early-stage venture developing an idea will have different needs than a venture that already has a finished product and some initial sales. An incubator is likely more appropriate for very-early-stage ventures. In fact, selection criteria of accelerators, which generally include initial traction in the market, differentiated technology, and potential to scale the business, might exclude such very-early-stage ventures. Table 1 summarizes perceived distinctions between incubators and accelerators from the Canadian survey respondents.

Respondents to the author's survey provided a variety of definitions and distinctions for the terms "incubator" and "accelerator", some of which were diametrically opposed. A few respondents used the analogy of an incubator for chicken eggs - "the role of the incubator is to grow the brand-new, hatched little chicks." Yet, others did not perceive any significant differences between the terms. Some of the managers indicated that their facility was both an incubator and an accelerator. Others mentioned that the word "incubator" had developed a negative connotation given the failure of Internet incubators following the dot-com crash in the early 2000s and that therefore, the word fell out of favour. Given this apparent confusion, entrepreneurs should focus on their needs relative to the specific types of support offered, and not what label a program gives itself. 


\section{Factors Affecting a Technology Entrepreneur's Choice of Incubator or Accelerator}

\section{Diane A. Isabelle}

Table 1. Distinctions between incubators and accelerators from the perspective of the Canadian survey respondents

\begin{tabular}{ll}
\hline \multicolumn{1}{c}{ Incubator } & \multicolumn{1}{c}{ Accelerator } \\
\hline For early-stage startups & $\begin{array}{l}\text { For next stage, for high-growth } \\
\text { firms }\end{array}$ \\
\hline Long-term process & Short-term process \\
\hline $\begin{array}{l}\text { Sectors with longer time to } \\
\text { market }\end{array}$ & $\begin{array}{l}\text { Sectors with shorter time to } \\
\text { market }\end{array}$ \\
\hline An institution & A program within an institution \\
\hline Building sustainable firms & $\begin{array}{l}\text { Short-term horizon, cohort- } \\
\text { based }\end{array}$ \\
\hline $\begin{array}{l}\text { More focused on economic } \\
\text { development }\end{array}$ & $\begin{array}{l}\text { More focused on growth and } \\
\text { ROI }\end{array}$ \\
\hline Generally not-for-profit & Generally for-profit \\
\hline Older establishments & $\begin{array}{l}\text { Newer establishments or } \\
\text { programs }\end{array}$ \\
\hline
\end{tabular}

\section{Fit between the entrepreneur's needs and incubator's mission, purpose, and sector focus}

Incubators are most successful, and hence so are their client firms, when their mission and goals correspond with the specific needs of the region's entrepreneurs and the incubators' sponsoring organizations. It is therefore imperative for entrepreneurs to have a good understanding of the mission and goals of any incubator or accelerator under consideration. However, the diversity of Canadian incubators, accelerators, and "hybrid" models makes it challenging for entrepreneurs to muddle their way through potential options. This situation is exacerbated by the various lifecycle stages of such support organizations. Some are in start-up mode, others are in a business-development stage, and yet others are in a maturity stage. Half of the respondents in the NBIA survey were from incubators that had opened in the last 10 years, including almost one-third that represented incubators that began operations since 2007.

Beyond growth stage and age, there are other aspects of incubators that make the evaluation process challenging for entrepreneurs. For example, some older organizations have evolved into a new model, while some mature organizations have merged together to become an incubator or accelerator. Some are very large such as the MaRS Discovery District (marsdd.com) in Toronto, others have only been recently set up. Some offer local or regional services, while others aim to provide virtual services nationally. As well, some have dual missions of supporting the regional development of new ventures and supporting the local universities, for instance Innovate Calgary (innovatecalgary.com) and the Genesis Centre in Newfoundland (genesis.mun.ca/GenesisCentre/), so are in effect a hybrid of an incubator and a technology transfer office. In fact, some of the managers interviewed by the author found it challenging to articulate their mission. For example, one respondent replied "We're not an accelerator. We're an incubator, but we're more than an incubator." Another replied: "We're kind of an accelerator-Plus." To make matter worse, some call their organizations incubators, while they are in fact accelerators, and likewise. The NBIA survey reported that three goals - creating jobs for the local community, fostering the community's entrepreneurial climate, and building or accelerating growth of local industry - received highest ratings. Commercializing technologies was rated fifth in importance. However, the NBIA survey covered all types of incubators, not only technology incubators. The recommendation for entrepreneurs then, is to look at the actual focus of activities for a given incubator or accelerator: is it about nurturing the very early stage of a firm? Or developing it? Or is it about technology incubation? Commercialization? A boot camp? Others?

Although mixed-use incubation - incubators working in a variety of industries - is the most prevalent type of incubation program, there is a growing trend toward incubation in specific industry sectors. Hence, most incubators and accelerators in North America focus on ICT, software, mobile applications, wireless technology, and related areas. A few target the bioscience/life science areas. Other sectors include healthcare technology, medical devices, and "cleantech". Entrepreneurs must ensure that their industry sector is an area of focus of any incubator they are evaluating.

In addition to looking at the mission and goals of incubators and accelerators, entrepreneurs should pay attention to the reputation of the organizations under consideration. Performance measures such as management effectiveness, occupancy rate, number of clients, and external performance measures such as survival rates of firms, jobs created, external investments raised, royalties collected, and valuation of companies could provide indications of overall effectiveness. However, such measures might not be readily available to potential client firms, not to mention that some incubators or accelerators may not have formal graduates yet. The 


\section{Factors Affecting a Technology Entrepreneur's Choice of Incubator or Accelerator}

Diane A. Isabelle

reputation of the incubator or accelerator is a crucial factor in the decision because it will increase the visibility of the firm, which in turn will help the firm attract capital, resources, and talent.

\section{Selection and graduation policies}

When selecting firms, incubators and accelerators apply selection criteria, which depend on the focus of the organization as well as whether it considers itself an incubator or an accelerator. Incubators and accelerators typically carry out an initial needs assessment and evaluate each candidate firm's fit with the mission of the organization and the industry sector, and they check that the firm meets any geographical location requirements (if applicable). In addition to these criteria, entrepreneurs must be aware that the "coachability" of the entrepreneurs was the next selection criterion most often mentioned by the Canadian managers of incubators and accelerators that were interviewed by the author. In addition to these criteria, accelerators tend to look at high growth potential, team composition and experience, existing prototypes, intellectual property, and market opportunities.

When a firm moves on from an incubator or accelerator, it is said to have "graduated". However, graduation policies vary across organizations, and therefore entrepreneurs should examine the policies of each organization under consideration. In the organizations surveyed by the author and the NBIA, these policies typically trigger a firm's graduation when the incubator or accelerator no longer adds value to the firm, when a firm exceeds a specific amount of office space or number of employees, or after a fixed period of time. However, there seems to be flexibility in the application of these policies. Overall, graduation policies have shifted from time limits to policies based on client growth and development. Still, entrepreneurs should try to anticipate their needs for employees and space so that they do not find themselves in a situation of having to move out at an inopportune time.

Graduation policies for accelerator programs are different: they tend to have a predetermined time limit. For instance, several accelerator programs in Canada are modeled after US programs such as $\mathrm{Y}$ Combinator (ycombinator.com) and TechStars (techstars.com), in which firms have 90 days to conceive, build, and launch a product into the market. Entrepreneurs must be mindful that such programs were perceived by some respondents of the author's survey as being too short for the Canadian context, which includes lower availability of venture capital relative to the United States. Other re- spondents expressed the view that these programs tended to focus too much on prepping up the technology entrepreneurs for the "big demo day" with investors, but that there was little follow up once the program was over, and consequently no real sustainable businesses. Others, however, see a continuum from an incubator to an accelerator program to develop the new venture toward successful commercialization and long-term sustainability.

\section{Nature and extent of services}

Incubators provide entrepreneurs with a broad array of services to help them get their ventures off to a successful start. Carayannis and von Zedtwitz (2005; tinyurl.com/caay6aa) have identified five defining services of incubation business models: i) access to physical resources, ii) office support, iii) access to financial resources, iv) entrepreneurial start-up support, and v) access to networks. Because incubators are speeding up business development and reducing uncertainty, Carayannis and von Zedtwitz believe that organizations offering fewer than four of these services lack too many elements of incubation to be considered incubators. Respondents from both surveys considered the following services to be most important: office space, help with business basics, marketing assistance, technology commercialization, links to strategic partners and access to investors.

Entrepreneurs must be mindful that smaller or newer incubators may offer fewer services, and that incubators and accelerators do not generally provide direct technical assistance with product development, but rather, link firms with external partners such as universities and research institutes. Other considerations include the number, expertise, and availability of staff staffing levels may range from a mere one employee to hundreds of employees, depending on the size and age of incubators. Past research has shown that high-quality management with business expertise and past work experience in the private sector is a strong contributing factor to the success of a technology incubator (OECD, 2010; tinyurl.com/cb89gw3). Yet, the NBIA survey notes that many incubation programs continue to experience very lean staffing and might be trying to do more with less. Therefore, entrepreneurs should pay attention to the ratio of staff to both tenant and offsite firms.

Another important aspect is the sponsoring entities and availability of funding - generally provided by government, economic-development organizations, academic institutions, and, less frequently, private sources. The NBIA reports that these types of organizations have ex- 


\section{Factors Affecting a Technology Entrepreneur's Choice of Incubator or Accelerator}

Diane A. Isabelle

perienced strained budgets during the recent economic downturn, leading to the scaling back of some existing incubation programs. In Canada, the recent Economic Action Plan (actionplan.gc.ca) includes dedicated funding to support entrepreneurship; however, there is no specific federal program to fund incubators and accelerators. Consequently, incubator managers must dedicate a fair amount of time to the management of multiple sources of funding, and this is time taken away from assisting entrepreneurs and developing networks. Entrepreneurs should seek to gain insight into the functioning of the incubator or accelerator. Where do they get their funding from? When does it expire? Are there any threats to ongoing funding? Are the services over subscribed? What is the amount of time that staff and network can realistically dedicate to firms? Also, if equity is involved, entrepreneurs must understand the potential short- and long-term impacts on their venture.

The NBIA survey reports that many incubation programs have expanded their service offerings to assist entrepreneurs at all stages of business development, that is pre- and post-incubation services. These services allow their programs to reach a broader audience of entrepreneurs, diversify their revenues streams, and raise their visibility in the business community. In fact, $2 \%$ of respondents reach an international customer base, a figure that although small is perhaps indicative of the larger trend of increased interest in doing business globally.

Several Canadian managers of incubators and accelerators mentioned offering a mixed approach of physical as well as virtual services to offsite clients. However, client firms interviewed by the author were generally not positive toward the virtual approach, citing in particular the need for face-to-face contacts with advisors, other tenants, and network partners. To quote one: "Long-distance mentorship is not effective." Another mentioned: "If it's $100 \%$ virtual then you lose a whole lot of the communication that is absolutely mandatory if the government funds are going to achieve their aim." The NBIA survey notes that, despite increased interest in virtual incubation, the vast majority of incubators (93\% of respondents) continue to have an incubation facility in which they house and assist client firms.

\section{The network of partners}

A critical component of the services offered by incubators and accelerators is an extensive network of advisors, "entrepreneurs in residence", partners, and service providers to complement the business assistance provided to technology entrepreneurs by the incubator staff. For instance, several incubators house representatives from organizations offering services in accounting and financial management, marketing assistance, intellectual property management, and legal services to support entrepreneurs. In-house support or linkages to strategic partners, technology commercialization partners, and to higher-education resources can also be provided. In the ICE (information technology, communications, and entertainment) sector, some incubators and accelerators have established strategic alliances with large firms such as Microsoft so that entrepreneurs can develop and test applications. Furthermore, an important function of incubators and accelerators is to help entrepreneurs access funding. Incubators and accelerators can provide access to angel investors, venture capital investors, and commercial banks. In addition, entrepreneurs can access government assistance programs such as National Research Council's Industrial Research Assistance Program (IRAP; nrc-cnrc.gc.ca/eng/irap/) in Canada and the Small Business Administration (SBA; sba.gov) in the US. Thus, an important aspect for entrepreneurs to consider is the availability of advisors, mentors, or coaches (paid? volunteer? part-time? fulltime?) and the nature and quality of the service providers.

\section{Conclusion}

Across North America and around the world, business incubators and accelerators are seen as playing a vital role in promoting innovation and economic growth through their efforts to help entrepreneurs turn their business ideas into profitable, sustainable new ventures. In spite of the measurement challenges mentioned above, most research suggests that ventures graduating from incubation programs have higher survival rates than non-incubated ventures.

In conclusion, when deciding whether or not to join a technology incubator or accelerator, a technology entrepreneur should consider five factors:

1. The stage of their new venture. Incubators are generally better suited to a very-early-stage venture whereas an accelerator tends to focus on growing a firm quickly.

2. The fit between the entrepreneur's needs and incubator's mission, purpose, and sector focus. With the proliferation of incubators and accelerators, technology entrepreneurs must pay close attention to their shortand long-term needs to ensure an adequate fit with potential incubators or accelerators. 


\section{Factors Affecting a Technology Entrepreneur's Choice of Incubator or Accelerator}

Diane A. Isabelle

3. The selection and graduation policies. Entrepreneurs should also consider the flexibility in how these policies are applied.

4. The nature and extent of services provided. Here, technology entrepreneurs need to objectively assess their most urgent needs and the capacity of the incubator or accelerator to meet these needs in a timely fashion, and at a reasonable fee.

5. The network of partners. Entrepreneurs should look for a variety of expertise to support firms (e.g., legal, regulatory, technical, intellectual property, finance).

The concept of incubators, and especially accelerators, is relatively new in Canada and is evolving. There is therefore a need for more analysis of their operations and effectiveness. Further, much attention has been focused on the ICT and related short time-to-market sectors. Therefore, less is known about the effectiveness of incubators and accelerators with longer time-to-market sectors such as biotechnologies and the life science sector. In addition, few services are offered by incubators and accelerators to support the internationalization efforts of entrepreneurs. These and other gaps in our knowledge about incubators and accelerators are opportunities for future research.

\section{About the Authors}

Diane Isabelle is a faculty member at Carleton University's Sprott School of Business, where she teaches marketing, entrepreneurship, and international business. She is also the principal of Diane Isabelle \& Associates Consultants. She was formerly the Executive Director to the Vice-President Physical Sciences at the National Research Council of Canada, and was for many years an Industrial Technology Advisor for NRC-Industrial Research Assistance Program (IRAP), supporting Canadian SMEs with the strategic use of innovation and business advice to compete on the global scene. She holds a $\mathrm{PhD}$ in management, an MBA, and an undergraduate engineering degree. Her areas of expertise include: technology entrepreneurship; strategic planning and foresight; and national and international initiatives in science and technology. Her research interests include: international collaborations, national innovation systems, science and technology commercialization, and other topics related to technology entrepreneurship and innovation management. She is the author of publications and communications in the field of innovation.

Citation: Isabelle, D.A. 2013. Key Factors Affecting a

Technology Entrepreneur's Choice of Incubator or

Accelerator. Technology Innovation Management Review.

February 2013: 16-22. 